\title{
Clear-Sky Surface Solar Radiation during the South China Sea Monsoon Experiment
}

\author{
Po-Hsiung Lin ${ }^{1}{ }^{*}$, Ming-Dah Chou ${ }^{2}$, Qiang $\mathrm{Ji}^{3}$, and Si-Chee Tsay ${ }^{2}$ \\ (Manuscript received 12 November 2001, in final form 16 April 2002)
}

\begin{abstract}
Downward total solar fluxes measured at Dungsha coral island ( $20^{\circ} 42$ ' $\mathrm{N}$, $116^{\circ} 43^{\prime} \mathrm{E}$ ) during the South China Sea Monsoon Experiment (May-June 1998) have been calibrated and compared with radiative transfer calculations for three clear-sky days. Model calculations use water vapor and temperature profiles from radiosonde measurements, and the aerosol optical thickness is derived from sunphotometric radiance measurements. Results show that the difference between observed and model-calculated downward surface fluxes is $<3 \%$ of the daily mean. Averaged over the three clear days, the difference reduces to $1 \%$. The averaged downward surface fluxes from observations and calculations for the three selected dates are 314 and $317 \mathrm{~W} / \mathrm{m}^{2}$, respectively. This result is consistent with a previous study using TOGA COARE measurements, which found good agreement between observations and model calculations. This study provides an extra piece of useful information for the modeling of radiative transfer, which helps to fill in the puzzle of the absorption of solar radiation in the atmosphere.
\end{abstract}

(Key words: SCSMEX, Surface solar radiation)

\section{INTRODUCTION}

The validity of radiation model calculations of atmospheric solar (shortwave, or SW) heating has long been an unsettled issue. Traditionally, this issue concems primarily the excess atmospheric heating due to the presence of clouds that is not accounted for in radiation model calculations (Cess et al. 1995; Pilewskie and Valero 1995). Other studies have shown that there is no clear evidence of enhanced solar heating of the atmosphere due to clouds (Imre et al. 1996; Li et al. 1997). Traditionally, the effect of clouds on the solar heating of the atmosphere (or atmospheric cloud radiative forcing, CRF) is estimated by taking the difference

\footnotetext{
'Department of Atmospheric Sciences, National Taiwan University, Taipei, Taiwan

${ }^{2}$ NASA Goddard Space Flight Center, Greenbelt, Maryland

${ }^{3}$ Science Systems and Applications, inc., Lanham, Maryland

${ }^{\star}$ Corresponding author address: Dr. Po-Hsiung Lin, Dept. of Atmospheric Sciences, National Taiwan University. \#1, section 4, Roosevelt Road, Taipei, 106, Taiwan; E-mail; linpo@atmos.as.ntu.edu.tw
} 
between the solar heating of the atmosphere in clear and cloudy skies. Thus, uncertainties about SW heating of both clear and cloudy skies could affect the estimation of the atmospheric CRF. In a study of the global radiation data sets derived from surface measurements, satellite retrievals, and climate model simulations, Arking (1996) suggested that clouds had little effect on the atmospheric solar heating. Rather, the large atmospheric CRF as estimated by some investigators was caused by the underestimation of water vapor heating in clear atmospheres, which affects the CRF estimation. Subsequently, a number of studies were made on the clearsky solar heating of the atmosphere and the surface, which used various types of measurements (total, spectral, direct, and diffuse radiation) at various geographical locations. Some studies have suggested that radiation models highly underestimate the clear-sky atmospheric heating and; hence, overestimate the surface heating (Kato et al. 1997; Halthore et al. 1998; Arking 1999; Pilewskie et al. 2000). Other studies have found agreement between observations and model calculations (Chou and Zhao 1997; Conant et al. 1998; Fu et al. 1998). Resolving this issue is very important because our ability to model the absorption of solar radiation affects the reliability of climate model simulations and remote sensing of a wide range of geophysical parameters.

In May and June 1998, there was an intensive field experiment, the South China Sea Monsoon Experiment (SCSMEX), conducted in the South China Sea. The SCSMEX was an international field experiment to study physical processes and evolutions of the water and energy cycles of the East Asian monsoon system (Lau et al. 2000). A suite of instruments was set up at Dungsha $\left(20^{\circ} 42^{\prime} \mathrm{N}, 116^{\circ} 43^{\prime} \mathrm{E}\right)$ to measure surface radiation and atmospheric temperature, humidity, and aerosols. Dungsha is a small coral island with a length of $\sim 1 \mathrm{~km}$ and a width of $\sim 0.7 \mathrm{~km}$. We use the data measured at Dungsha to study the surface SW radiation and compare the observations with radiation model calculations. Results of the comparison provide us information on whether the large CRF as estimated by some investigators is caused by the uncertainty in the model calculations of SW radiation in clear atmospheres.

\section{SURFACE MEASUREMENTS AND RADIATIVE TRANSFER MODEL}

Propagation of the East Asian summer monsoon system (EASM) during the spring-summer ransition period influences the annual rainfall variation in the South China Sea. To understand the role of the EASM in the global energy and water cycle and to improve the simulation and prediction of East Asian monsoon and regional water resources, observations were conducted during two SCSMEX intensive observation periods (IOP). The first IOP was conducted during 5-25 May 1998 to observe atmospheric and oceanic circulation before the monsoon passed through the South China Sea. The second IOP was conducted during 5-25 June 1998 to observe tropical weather under the influence of EASM.

In addition to the weather stations operated by the Taiwanese navy, other advanced facilities were also in use on Dungsha during the SCSMEX IOP. These facilities included Australian C-band polarization radar system, unmanned aerial vehicle "Aerosonde", National Center for Atmospheric Research (NCAR) Integrated Sounding System (ISS), and a NASA radiation measurement system. Radiative fluxes were measured in the period from 17 April through 6 July 1998. Three Epply Precision Spectral Pyranometers (PSP) and one Yankee Total Spectral 
Pyranometer were used to measure surface downward SW fluxes. The Epply pyranometers measured fluxes in the ultraviolet $(0.3 \sim 0.4 \mu \mathrm{m})$, photosynthetically active radiation $(0.4 \sim 0.7$ $\mu \mathrm{m})$, and infrared $(0.7 \sim 2.8 \mu \mathrm{m})$ spectral bands. Two Epply Precision Infrared Radiometers (PIR) were used to measure the downward longwave fluxes. A CIMEL 318-1 sunphotometer and a Yankee six-channel Multifilter Rotating Shadowband Radiometer (MFR-6) were used to measure direct- and sky-radiation. A single data-acquiring system processed and stored all radiative flux measurements with a one-minute sampling rate.

Except for the CIMEL component, all of the radiation measurement facilities and the data acquiring system were new products with operating functions checked by the manufacturer in February 1998. After the SCSMEX campaign, all instruments were brought back to NASA/ Goddard Space Flight Center for re-calibration. The pyranometer current equivalent to zero solar radiation was obtained by applying the dark-current checking procedure ( $\mathrm{Ji}$ and Tsay 2000). The methodology involved the use of aluminum-made caps to cover the outer glass dome of the pyranometers during daytime operation. The overall uncertainty of the radiation measurements, including data-logger performance, is estimated to be $3 \%$.

The aerosol optical thickness (AOT) was retrieved from the radiances measured by the Cimel Electronique CE318-1 automatic sun-tracking photometer. This instrument had seven filters centered at $340,380,440,500,675,870$, and $1020 \mathrm{~nm}$. Two collimators with 1.2 degrees were used to measure direct- and sky-radiances every $15 \mathrm{~min}$. The measured-radiances were sent to the NASA Aerosol Network office (Holben et al. 1998) for AOT retrieval. The uncertainty of AOT under a clear-sky situation was estimated to be $<0.01$ for wavelengths $>$ $440 \mathrm{~nm}$ and $<0.02$ for shorter wavelengths. Since the contribution of sea salt to AOT is small relative to that of the sulfuric particles, the aerosol single-scattering albedo is set to 0.996 and the asymmetry factor is set to 0.786 . These values are typical of the maritime sulfuric aerosols as inferred using radiances measured by the NASA Sea-viewing Wide Field-of-view Sensor (SeaWiFS) project (Wang et al. 2000).

The Integrated Sounding System (ISS) GPS-based balloon sounding was launched twice a day at 0600 UTC and 1800 UTC. Vaisala RS80-15G radiosonde was used in this balloon sounding system to measure the atmospheric temperature and humidity profiles. The temperature sensor, THERMOCAP, has a $0.2 \%$ accuracy up to $50 \mathrm{hPa}$, and the humidity sensor, HUMICAP, has a $3 \%$ accuracy. It is found that the measured column water vapor amount agrees well with that retrieved from the Special Sensor Microwave Imager (Wentz 1994) and the CIMEL radiance measurements at $940 \mathrm{~nm}$.

We use the solar radiative transfer model (CLIRAD-SW) developed at the NASA Goddard Climate and Radiation Branch (Chou and Suarez 1999) to compute the downward surface SW flux at Dungsha. The model has been applied to various atmospheric models used in the Goddarad Laboratory for Atmospheres, including a general circulation model, a mesoscale model, and a cloud ensemble model. It includes the absorption due to water vapor, $\mathrm{O}_{3}, \mathrm{O}_{2}$, $\mathrm{CO}_{2}$, clouds, and aerosols. Interactions among the absorption and scattering by clouds, aerosols, molecules (Rayleigh scattering), and the surface are fully taken into account. Fluxes are integrated virtually over the entire spectrum, from 0.175 to $10 \mu \mathrm{m}$. Integrated over all spectral bands and all absorbers, the surface heating is computed accurately within a few watts per meter squared of high spectral-resolution calculations. 
The pyranometer measurements of SW flux at Dungsha did not include radiation in the spectral region $2.8 \sim 10 \mu \mathrm{m}$. For comparisons between measured and computed surface fluxes, radiation in this spectral region has to be taken into consideration. Line-by-line calculations, which use the 1996-version of the AFGL molecular line parameters (Rothman et al. 1998) with a line-cutoff of $10 \mathrm{~cm}^{-1}$, show that the range of the surface flux in this spectral region ranges only from 10.8 to $12.8 \mathrm{Wm}^{-2}$ for the column water vapor amount ranging from 2.8 to $5.6 \mathrm{~cm}$ when the sun is overhead. Therefore, we fit the surface flux computed for a column water vapor amount of $3 \mathrm{~cm}$ as a function of the solar zenith angle. The total flux computed using the SW radiation model is then reduced by an amount derived from this function to remove the radiation contained in the spectral region $2.8 \sim 10 \mu \mathrm{m}$.

\section{COMPARISONS OF MEASURED AND CALCULATED SURFACE SW FLUXES}

In the tropical western Pacific and the South China Sea, clouds are widespread, and it is difficult to identify radiation measurements which are free of cloud influence. In studying the surface radiation in the Pacific warm pool during the Tropical Ocean and Global Atmosphere, Coupled Ocean-Atmosphere Response Experiment (TOGA COARE), Chou and Zhao (1997) used both the direct and the diffuse components of the SW radiation to identify clear-sky surface fluxes. Based on the observed facts, in a cloud-free atmosphere the direct radiation is large, the diffuse radiation is small, and the diumal variation of the total surface radiation is in accordance with the incoming radiation at the top of the atmosphere. We examined the diurnal variation of the total surface radiation and subjectively identified three days ( 2 May, 22 May, and 29 June 1998) as being mostly clear. For these three clear days, the total surface radiation (dashed curves in Fig. 1) is large and varies smoothly with time, following the radiation at the top of the atmosphere.

When clouds block the sun, the surface radiation is greatly reduced. When clouds do not block the sun but are scattered over the observation site, the surface radiation is greater than that for clear skies. Thus, clouds could either increase or decrease the surface radiation depending upon the relative locations of clouds, the sun, and the surface site. These situations can be clearly seen in Fig. 1 (dashed curves). To estimate the clear-sky surface downward SW radiation, $\mathrm{F}^{\downarrow}$, of those mostly clear days, we make the following adjustments to the measured surface radiation. First, we delete data which are obviously affected by clouds. For example, the data in the early morning and late afternoon on 2 May (Fig. 1a). Second, the remaining data are fit by a third-order polynomial function of the solar zenith angle, $\mu_{0}$, separately for morning and afternoon data. It is found that $\mathrm{F}^{\downarrow}$ varies rather linearly with $\mu_{0}$, and the third-order polynomial function fits well the surface radiation. Third, we further delete data that deviate from the regression curves by $>15 \mathrm{Wm}^{-2}$. The remaining data are further fit by a third-order polynomial function of $\mu_{0}$, again separately for morning and afternoon data. Finally, we replace the data deleted in the first and third steps by that computed from the regression curves. The diumal variations of the reconstructed $\mathrm{F}^{\downarrow}$ are shown by the solid curves in Figs. 1arc.

Comparing Figs. 1a-c, Fig. 1c has the smoothest curve among them. This indicates that the atmosphere on 29 June was the clearest among the three days. Unfortunately, there were no balloon sounding and sunphotometer measurements, and humidity and aerosol information 

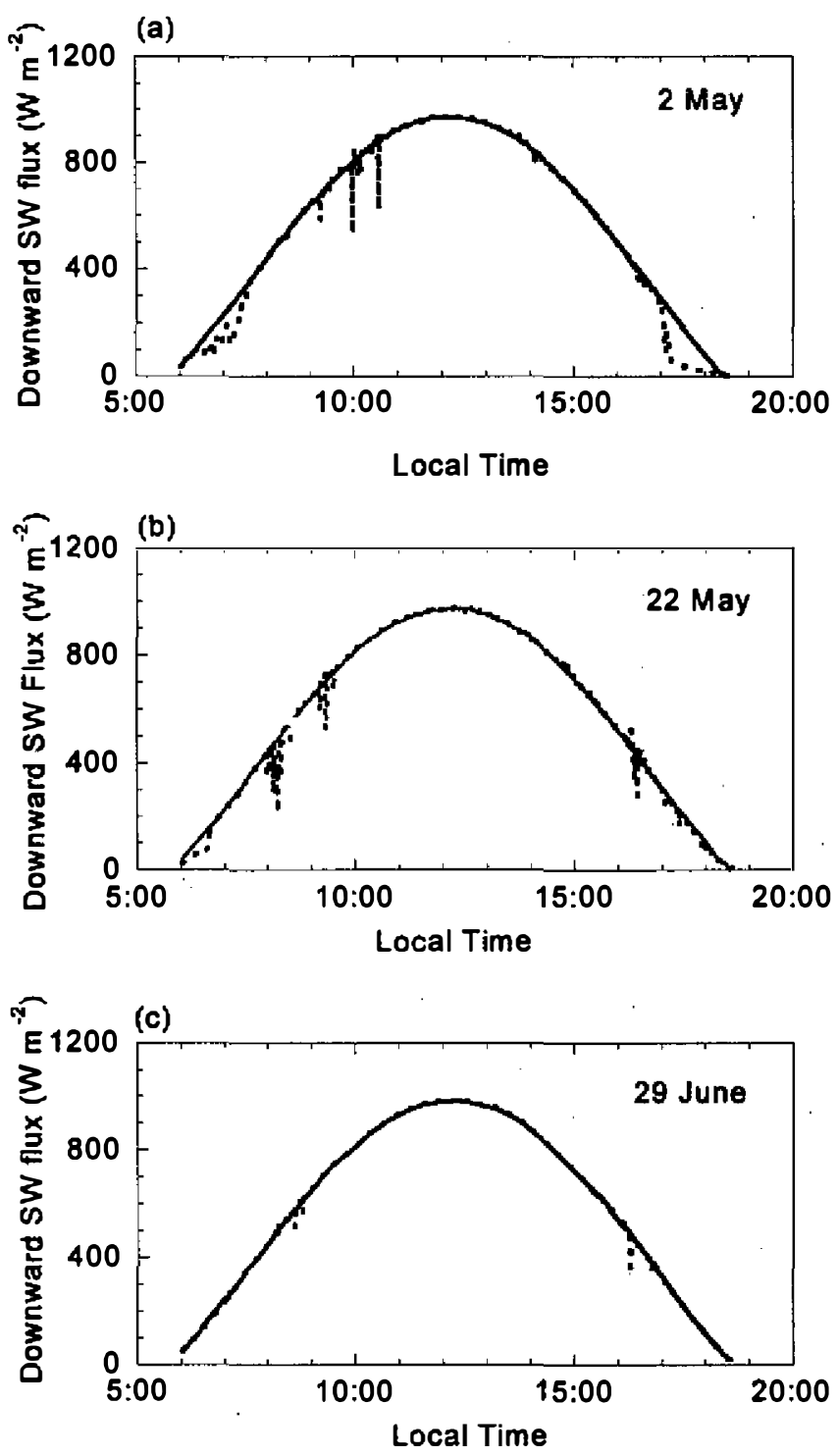

Fig. I. The surface downward SW flux measured by the Epply pyranometers (dashed curve), and the reconstructed clear-sky downward SW flux (solid curve).

were not available on that day. After the first surge of the monsoon passing through Dungsha on 10 June 1998, there was nearly no rain on the island, and the standard deviation of the 12hourly column water vapor amount was only $0.4 \mathrm{~cm}$. Therefore, we use the water-vapor soundings on 22 June as a substitute for 29 June. Figure 2 shows the measured downward surface SW fluxes on 29 and 30 June. Although the cloud effect on the surface radiation was large on 30 June, the two curves overlap very well when there is no cloud interference. This indicates 


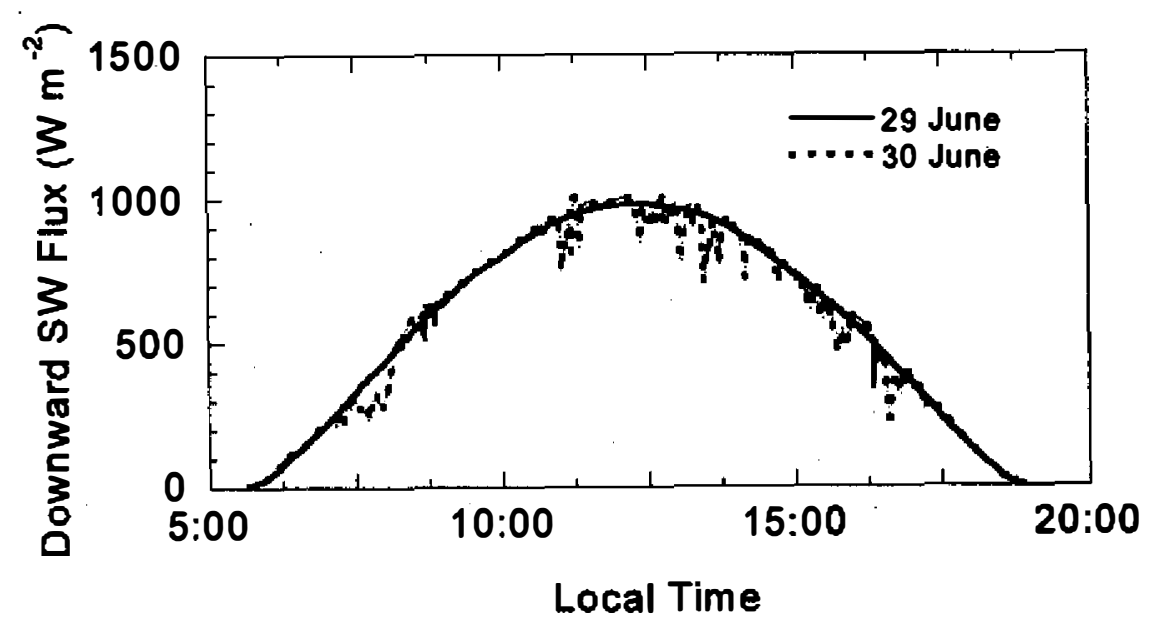

Fig. 2. The surface downward SW flux measured at Dungsha.

that the AOT is similar for both days. Therefore, we use the average AOT inferred for the moming on 30 June to compute the surface radiation on 29 June.

The AOT measurements for 2 May, 22 May, and 30 June are shown in Figs. 3a-3c, respectively. The AOT pattern for June 30 (Fig. 3c) depends weakly on wavelength, which is quite different from the other two clear days in May (Figs. 3a and 3b). The weather before the development of South China Sea summer monsoon was dominated by a quasi-stationary frontal system along the coastline of China. One can expect that fine-sized pollutants were transported southerly from China to the South China Sea. When the first transition period of the South China Sea monsoon developed in late May 1998, the weather system was dominated by the prevailing southwesterly wind. It is expected that most of the aerosol particles were sea salt and not the anthropogenic sulfuric aerosols from China. The weak dependence of AOT on wavelength shown in Fig. $3 \mathrm{c}$ is related to the large sea salt particles. Furthermore, the AOT of the maritime aerosols is much smaller than that of the continental aerosols (Figs. 3a and 3b).

Radiative fluxes are computed with the model of Chou and Squarez (1999). The radiosoundings of atmospheric temperature and humidity taken at 0600 UTC are used to represent the daytime conditions. Fluxes are computed at 1-min resolution. Information on the vertical distributions of aerosols and column-integrated ozone amount are not available for flux calculations. Therefore, we assume that aerosol optical thickness derived from the CIMEL sunphotometric measurement has a uniform vertical distribution below the $800 \mathrm{hPa}$ level. Sensitivity tests show that the results are not sensitive to the assumed thickness of the aerosol layer. For an aerosol optical thickness $<0.3$ at the visible spectral region, the daily-mean downward surface flux changes by only $<0.5 \mathrm{Wm}^{-2}$ when the top of the aerosol layer is extended from the $800 \mathrm{hPa}$ to $600 \mathrm{hPa}$. The surface SW fluxes are also not sensitive to the ozone amount. For a change of the ozone amount from 0.30 to 0.35 (cm-atm), the daily mean surface SW flux reduces by $<0.5 \mathrm{Wm}^{-2}$. Therefore, we use an ozone profile typical of a mid-latitude summer atmosphere, which has column amount of 0.32 (cm-atm), in all calculations. 

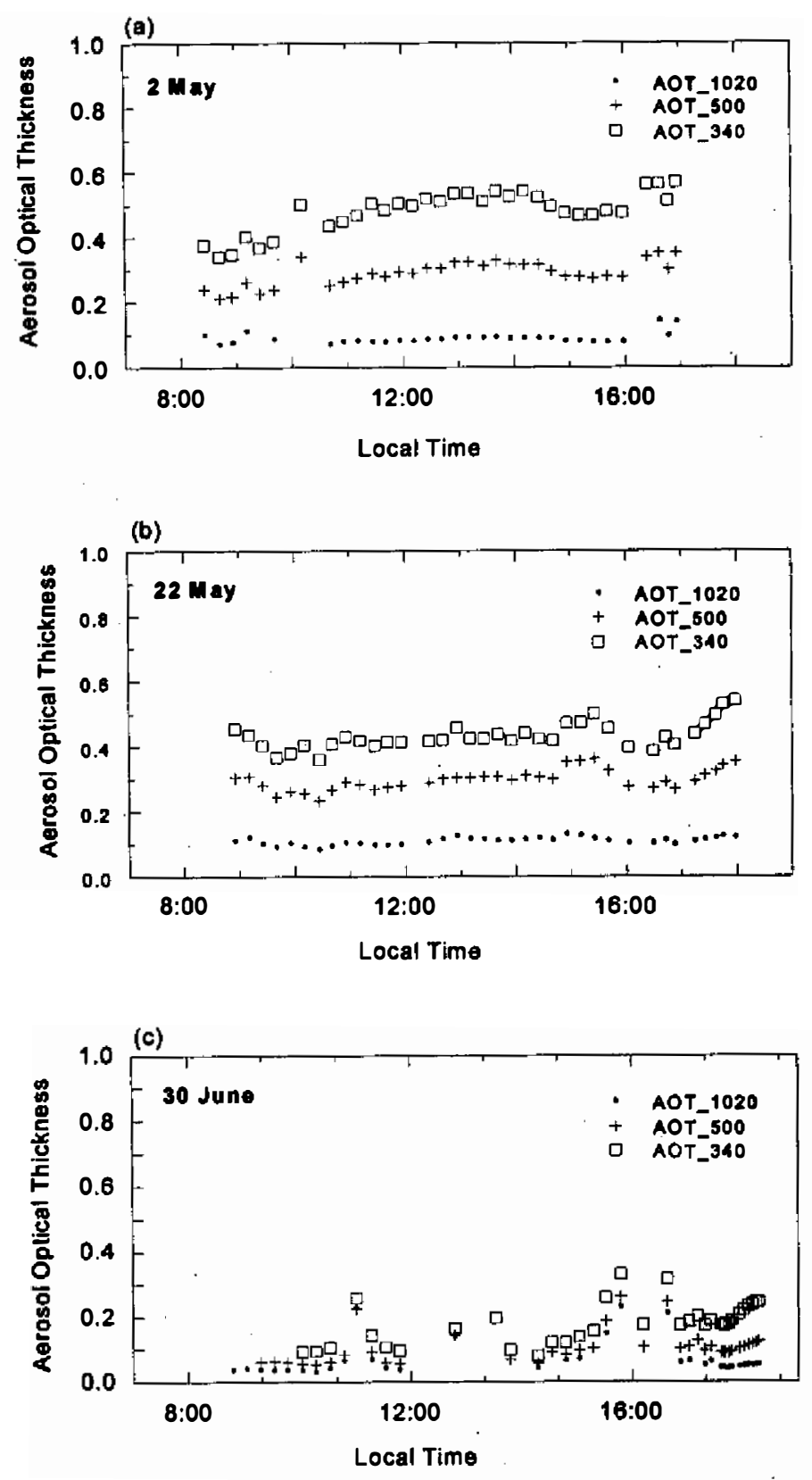

Fig. 3. The aerosol optical thickness retrieved at Dungsha.

Figure 4 shows diurnal variations of the incoming solar flux at the top of the atmosphere (upper dashed curves), the reconstructed ( solid curves) and the model-calculated (dotted curves) $\mathrm{F}^{\downarrow}$. Diurnal distributions of the difference between the reconstructed and the calculated $\mathrm{F}^{\downarrow}$ are shown in Fig. 5. The large difference in the early morning and the late afternoon on 2 May 

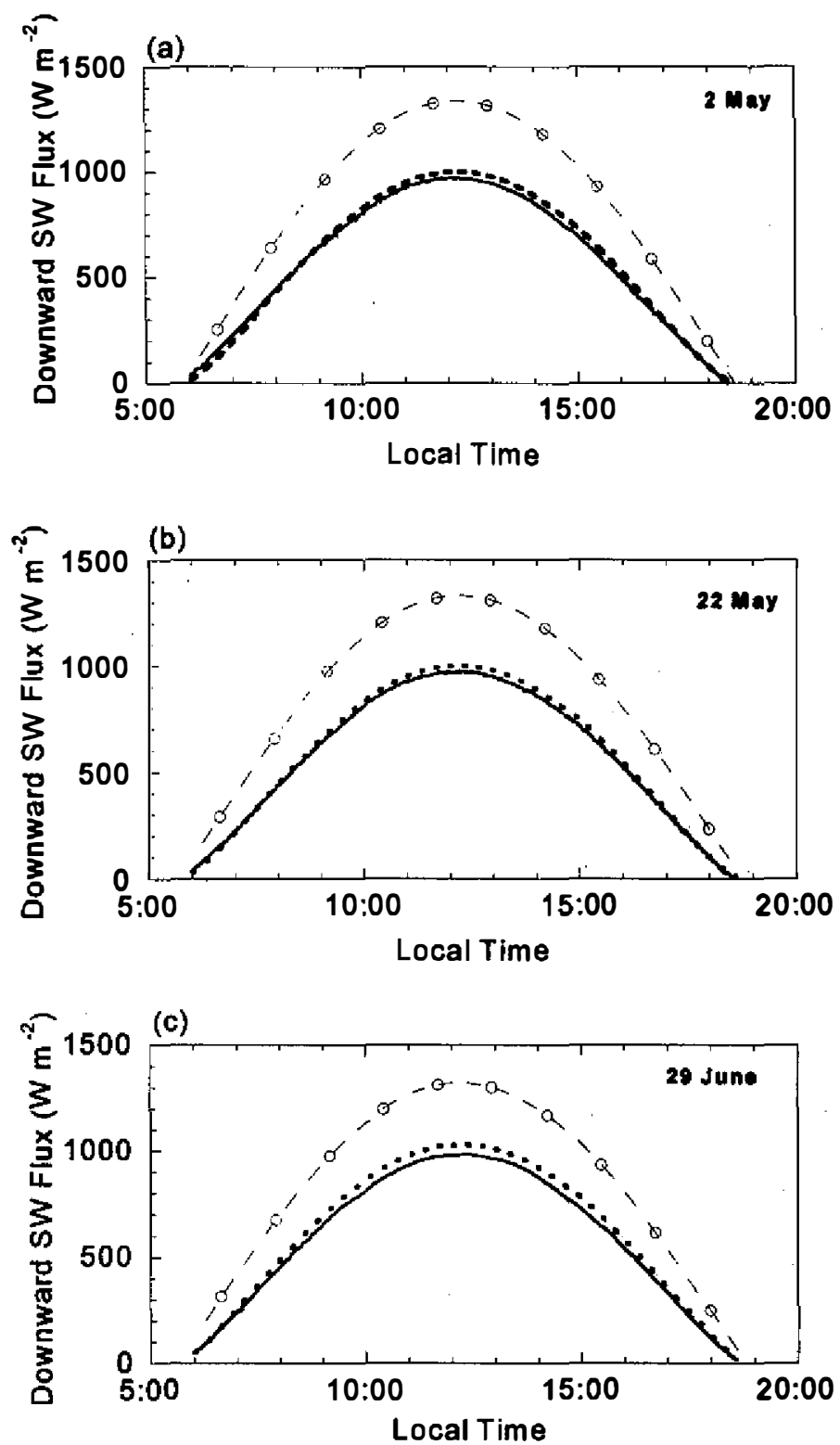

Fig. 4. Insolation at the TOA (upper dashed curve), the model-calculated (dotted curve) and the reconstructed (solid curves) surface downward SW fluxes.

is due to the extrapolation of the clear-sky flux to these hours when the sky was cloudy, as indicated in the measured surface flux shown in Fig. 1a (dashed curve). The relatively large bias of the model-calculated $\mathrm{F}^{\downarrow}$ on 29 June is due primarily to the lack of direct information on water vapor and aerosols. Table 1 summarizes the water vapor amount and the aerosol optical thickness used in the radiation model calculations, as well as the incoming SW flux at 


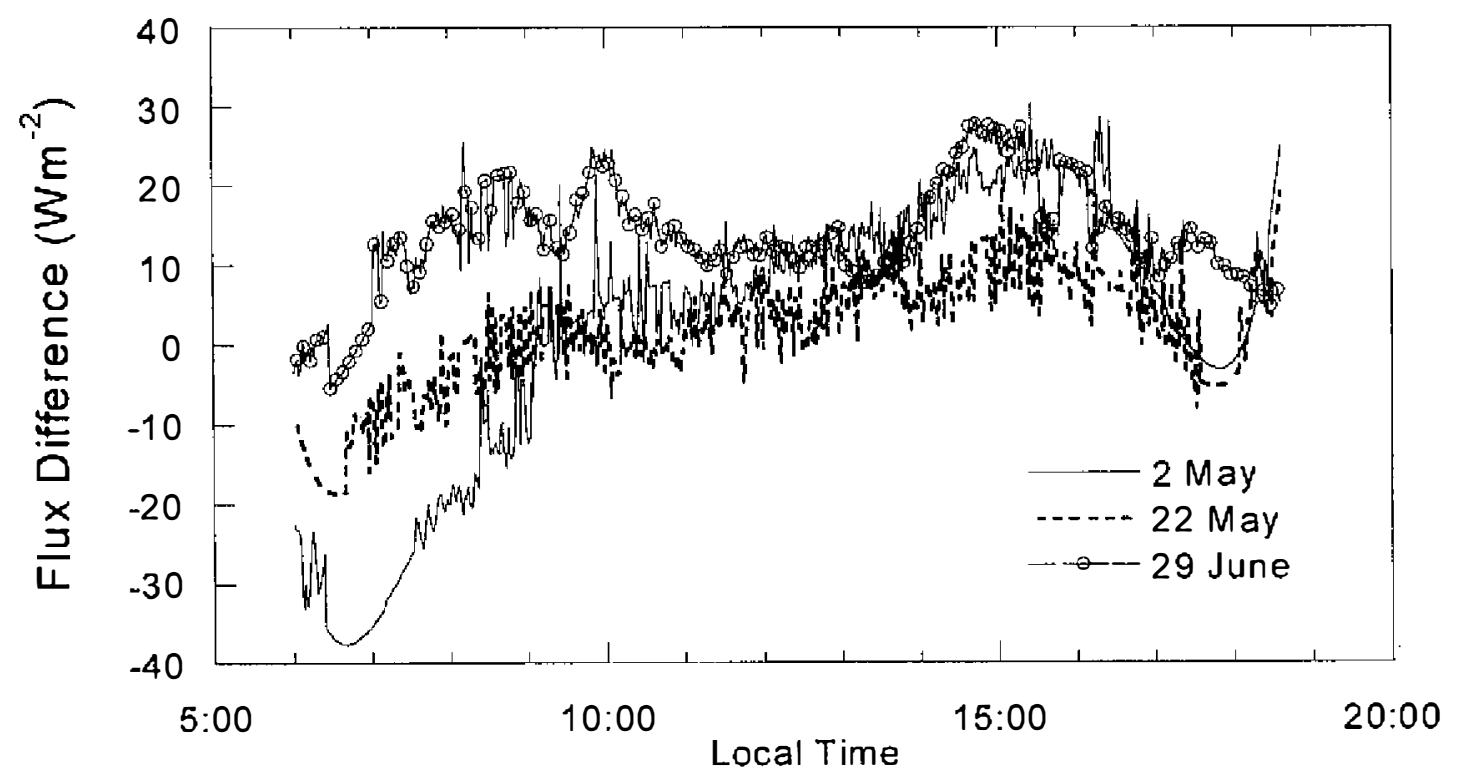

Fig. 5. Model-calculated surface downward flux minus reconstructed surface downward flux.

the top of the atmosphere, surface measurements, and model calculations. The daily mean difference between the reconstructed and the model-calculated $\mathrm{F}^{\downarrow}$ is $1.2,0.9$, and $7.1 \mathrm{Wm}^{-2}$ for 2 May, 22 May, and 29 June, respectively.

\section{CONCLUSION}

During the SCSMEX IOP, three days are found to be clear with minimal cloudiness at Dungsha. Diumal cycles of the clear-sky surface downward SW flux, $\mathrm{F}^{\downarrow}$, are reconstructed

Table 1. Daily mean values of the column water vapor amount $(\omega)$,aerosol optical thickness in the $\operatorname{UV}\left(\tau_{\mathrm{uv}}\right)$, visible $\left(\tau_{\mathrm{v}}\right)$, and infrared $\left(\tau_{\mathrm{ir}}\right)$ spectral regions, insolation at the top of the atmosphere $\left(\mathrm{S}_{\text {toa }}\right)$, reconstructed surface downward SW flux $\left(\mathrm{F}_{\mathrm{r}}^{\downarrow}\right)$, and model-calculated surface downward SW flux $\left(\mathrm{F}_{\mathrm{m}}^{\downarrow}\right)$.

\begin{tabular}{cccc}
\hline & May 2 & May 22 & June 29 \\
\hline$\omega(\mathrm{cm})$ & 5.6 & 5.9 & 5.6 \\
$\tau_{\mathrm{uv}}$ & 0.45 & 0.42 & 0.09 \\
$\tau_{\mathrm{v}}$ & 0.27 & 0.27 & 0.06 \\
$\tau_{\text {ir }}$ & 0.10 & 0.13 & 0.04 \\
$\mathrm{~S}_{10 a}\left(\mathrm{Wm}^{-2}\right)$ & 450.6 & 457.5 & 458.7 \\
$\mathrm{~F}^{\dagger}\left(\mathrm{Wm}^{-2}\right)$ & 308.1 & 312.6 & 319.7 \\
$\mathrm{~F}^{1}{ }_{\mathrm{m}}\left(\mathrm{Wm}^{-2}\right)$ & 309.3 & 313.5 & 326.8 \\
\hline
\end{tabular}


by removing the effect of clouds based on the near-linear relationship between $\mathrm{F}^{\downarrow}$ and the cosine of the solar zenith angle. The reconstructed $\mathrm{F}^{\downarrow}$ on the three clear days are compared with radiative transfer model calculations. The input data to the model calculations include the temperature and humidity profiles from radiosoundings and the aerosol optical thickness inferred from sunphotometric radiance measurements. The difference between the measured and the model-calculated $\mathrm{F}^{\downarrow}$ is $<3 \%$ of the daily means, which is comparable to the estimated uncertainty of the surface measurements. The result is consistent with a previous study using TOGA CAORE measurements, which found good agreement between observations and model calculations. Averaged over the three clear days, $\mathrm{F}^{\downarrow}$ is $314 \mathrm{Wm}^{-2}$ from observations and 317 $\mathrm{Wm}^{-2}$ from model calculations.

Previous studies on $\mathrm{F}^{\downarrow} 1$ by other investigators gave mixed results. Some showed good agreement between model-calculated and measured $\mathrm{F}^{\downarrow}$. Others showed significant disagreement. Those studies covered different geographic locations in the tropical western Pacific and the U.S. Department of Energy ARM (Atmospheric Radiation Measurement) sites. Whether radiative transfer models overestimate the surface radiation, or equivalently underestimate the atmospheric absorption, is likely to remain an issue for some time to come. The results of this study provide an extra piece ef useful information for the modeling of radiative transfer in a clear-sky atmosphere, which fills in the puzzle of the absorption of solar radiation in the atmosphere.

Acknowledgments The work conducted at the National Taiwan University was supported by National Science Council in Taiwan. The work conducted at the NASA Goddard Space Flight Center was supported by the Radiation Processes Program, NASA Office of Earth Science. The NASA Aeronet group processed the Cimel data. Prof. Pay-Liam Lin of National Central University, Taiwan, provided the ISS data set, and the Dungsha Weather Station, Naval Meteorological Center, Taiwan, provided logistic support.

\section{REFERENCES}

Arking, A., 1996: Absorption of solar energy in the atmosphere: discrepancy between model and observation. Science, 273, 779-792,

Arking, A., 1999: The influence of clouds and water vapor on atmospheric absorption. Ceophys. Res. Lett., 26, 2729-2732,

Cess, R. D., M. H. Zhang, P. Minnis, L. Corsetti, E. G. Dutton, B. W. Forgan, D. P. Garber, W. L. Gates, J. J. Hack, E. F. Harrison, X. Jing, J. T. Kiehl, C. N. Long, J.-J. Morcrette, G. L. Potter, V. Ramanathan, B. Subasilar, C. H. Whitlock, D. F. Young and Y. Zhou, 1995: Absorption of solar radiation by clouds: Observations versus models. Science, 267, 496-499.

Chou, M. D., and W. Zhao, 1997: Estimation and model validation of surface shortwave radiation and cloud radiative forcing using TOGA COARE measurements. J. Climate, 10, 611-620.

Chou, M. D., and M. J. Suarez, 1999: A shortwave radiation Parameterization for atmospheric studies. Volume 15, Technical Report Series on Global Modeling and Data Assimilation, 
NASA/TM-1999-104606. pp40.

Conant, W. C., A. M. Vogelmann, and V. Ramanathan, 1998: The unexplained solar absorption and atmospheric $\mathrm{H}_{2} \mathrm{O}$ : a direct test using clear-sky data. Tellus, 50A, 525-533, 1998.

Fu, Q., G. Lesins, J. Higgins, T. Charlock, P. Chylek, and J. Michalsky, 1998: Broadband water vapor absorption of solar radiation tested using ARM data. Geophy. Res. Letter, 25, 1169-1172.

Halthore, R. N., S. Nemesure, S. E. Schwartz, D. G. Imre, A. Berk, E. G. Dutton, and M. H. Bergin, 1998: Models overestimate diffuse clear-sky surface irradiance: A case for excess atmospheric absorption. Geophy. Res. Letter., 25, 3591-3594.

Holben, N. L., T. F. Eck, I. Slutker, D. Tanre, J. P. Buis, A. Setzer, E. Vermote, J. A. Reagan, Y. J. Kaukman, T. Nakajima, F. Lavenu, I. Jankowiak, and A. Smirnov, 1998: AERONET - a federated instrument network and data archive for aerosol characterization. Remote Sens. Enviorn., 66, 1-16.

Imre, D. G., E. H. Abramson, and P. H. Daum, 1996: Quantifying cloud-induced shortwave absorption: An examination of uncertainties and of recent arguments for large excess absorption. J. Appl. Meteorol., 35, 1991-2010.

Ji, Q., and S. C. Tsay, 2000: On the dome effect of Epply Pyrgeometers and Epply Pyranometers. J. Geophys. Letter., 27, 971-974.

Kato, S., T. P. Ackerman, E. E. Clothiaux, J. H. Mather, G. G. Mace, M. L. Wesely, F. Murcray, and J. Michalsky, 1997: Uncertainties in modeled and measured clear-sky surface shortwave irradiances. J. Geophy. Res., 27, 25881-25898.

Lau, K. M., Y. Ding, J. T. Wang, R. Johnson, T. Keenan, R. Cifelli, J. Gerlach, O. Thiele, T. Rickenbach, S. C. Tsay, and P. H. Lin, 2000: A report of the field operations and early results of the South China Sea Monsoon Experiment (SCSMEX). Bull. Amer. Meteor. Soc., 81, 1261-1270.

Li, Z., L. Moreau, and A. Arking, 1997: On solar energy disposition: a perspective from observation and modeling. Bull. Amer. Meteor. Soc., 78, 53-70.

Pilewskie P., and F. P. J. Valero, 1995: Direct observations of excess solar absorption by clouds. Science, 267, 1626-1629.

Pilewskie, P., M. Rabbette, R. Bergstrom, J. Marquez, B. Schmid, and P. B. Russell, 2000: The discrepancy between measured and modeled downwelling solar irradiance at the ground: Dependence on water vapor. Geophy. Res. Letter, 27, 137-140.

Rothman, L. S., and co-authors, 1998: The HITRAN molecular spectroscopic database and HAWK (HITRAN Atmospheric Workstation): 1996 Edition. J. Quant. Spectrosc. Radiat. Transfer, 60, 665-710.

Wang, M., S. Bailey, and C. R. McClain, 2000: SeaWiFS provides unique global aerosol optical property data. EOS, Amer. Geophy. Union, 81, 197-202.

Wentz, F. J., 1994: User's Manual SSM/I -2. Geophysical Tapes. Tech. Rep. 070194, 20 pp, 1994. Available from Remote Sensing Systems, Santa Rosa, CA. 